\title{
Invited Response on: The Breast Implant ARC: An Algorithm for Determining the Position of the IMF in Breast Augmentation Planning
}

\author{
Werner H. Beekman ${ }^{1}$ (D)
}

Received: 29 August 2019/Accepted: 7 September 2019/Published online: 25 September 2019

(C) Springer Science+Business Media, LLC, part of Springer Nature and International Society of Aesthetic Plastic Surgery 2019

Level of Evidence $V$ This journal requires that authors assign a level of evidence to each article. For a full description of these Evidence-Based Medicine ratings, please refer to the Table of Contents or the online Instructions to Authors-www.springer.com/00266.

We are aware that our primary duty as plastic surgeons is to provide our patients with the most fitting implants according to the width, height and tissue characteristics of their breasts. Sometimes their wish is to have an implant size that mildly exceeds the width of the breast and then the trade-offs should be mentioned, as stated in the article. When exceeding the width of her breast, with the chosen implant, we are convinced that the trade-off of lateral palpability of the implants is more depending on the overdissection of the tissues laterally. That is why we advocate the limited dissection of the pocket laterally. The height of the implant is the surgeon's choice according to the pre-op measurements.

The external sizers are used for volume determination only, and not to predict the shape of the breast, as mentioned in the article. The surgeon translates the sizers into a corresponding size of the implant, with the most fitting width and height according to the pre-op breast measurements.

When focussing mainly on the width and height of the breast, many postoperative problems encountered in primary breast augmentations involve the lower pole: waterfall deformities, double-bubble phenomenon and bottoming out of the implants. That is why we focus on the lower pole also taking the width and height into account.

The measurements of the parenchyma are taken at the level of the nipple, thus measuring the soft tissues prepectorally, and are certainly not arbitrary. More than $90 \%$ of the primary augmentations in my practice are performed with a dual-plane technique with anatomical implants having consistent results and a very high satisfaction rate with never having a discussion about the implant volume.

For round implants, the $45 / 55$ ratio as described by Malluci is an excellent tool, but is not the focus of this article using anatomical implants.

\section{Compliance with Ethical Standards}

Conflict of interest The authors declare that they have no conflicts of interest to disclose.

Ethical Approval This article does not contain any studies with human participants or animals performed by any of the authors.

Informed Consent For this type of study, informed consent is not required.
Werner H. Beekman

whbeekman@kpnmail.nl

1 Department of Plastic Surgery, BeekmanKlinieken Hilversum, Van Linschotenlaan 1, 1212 ES Hilversum, The Netherlands 